\title{
Selective crystal growth regulation by chiral $\alpha$-hydroxycarboxylic acids improves the strength and toughness of calcium sulfate cements
}

Hanan Moussa ${ }^{1,2}$, Wenge Jiang ${ }^{1,3}$, Amir El Hadad ${ }^{1,4}$, Ammar A Alsheghri ${ }^{5}$, Tayebeh Basiri1, Doaa Taqi ${ }^{1}$, Jun Song ${ }^{5}$, Faleh Tamimi ${ }^{1,6^{*}}$

${ }^{1}$ Faculty of Dentistry, McGill University, Montreal, QC, Canada, H3A 0C7;

${ }^{2}$ Faculty of Dentistry, Benghazi University, Benghazi, Libya, 9504;

${ }^{3}$ Department of Chemistry, Tianjin Key Laboratory of Molecular Optoelectronic Sciences, and Tianjin

Collaborative Innovation Center of Chemical Science \& Engineering, Tianjin University, Tianjin, P. R.

China, 300072;

${ }^{4}$ Physics Department, Faculty of Science, Al-Azhar University, Nasr City, Cairo, Egypt, 11884;

${ }^{5}$ Department of Mining and Materials Engineering, McGill University, Montreal, QC, Canada, H3A 0C5;

${ }^{6}$ College of Dental Medicine, Qatar University, Doha, Qatar

KEYWORDS: gypsum cements, mechanical properties, chirality, carboxylic acid, crystal growth

*Corresponding author

(faleh.tamimimarino@mcgill.ca) 


\section{Supplementary Text: Compressive strength and fracture toughness models for gypsum cements}

1. Compressive strength model. A model for compressive strength $\sigma_{\text {comp }}$ of brittle polycrystalline materials as a function of crystal size $G$ and porosity $P$ was proposed by: ${ }^{1}$

$$
\sigma_{c o m p}=C G^{-a} e^{-b P}
$$

where $C, a$ and $b$ are constants. To determine these constants using the experimental data, we used nonlinear least-square data-fitting using MATLAB (Release 2017b, The MathWorks, Inc.,

Natick, Massachusetts, USA), which yielded $C=91.5 \mathrm{MPa} \mu \mathrm{m}^{0.26}, a=0.26$ and $b=2.05$ After substitution in Equation. (1):

$$
\sigma_{\text {comp }}=(91.5) G^{-0.26} e^{-2.05 P}
$$

Equation. (2) provides a precise prediction of the compression strength based on the experimental data with an R-value of 0.90 and a p-value of 0.001 (Figure $3 \mathrm{c}$ ). This model, as shown in (Figure 3e) in the main text, demonstrates that the compressive strength increases with decreasing both the porosity and the crystal size. Furthermore, it also shows that the effect of decreasing the crystal size on the compressive strength is more pronounced than decreasing the porosity.

2. Fracture toughness model. As far as fracture toughness is concerned, previous studies on the mechanical properties of hydroxyapatite ceramics found an exponential dependence of the fracture toughness on porosity in the form of $:^{2}$

$$
K_{I C}=K_{I C O} e^{-n P}
$$

where $K_{I C O}$ and $n$ are constants and $P$ is the porosity. Besides the dependence of fracture toughness on porosity, it is also widely reported that the crystal size may significantly affect the 
fracture toughness of ceramic materials. ${ }^{3}$ Comparing the experimentally measured fracture toughness and compressive strength (Figure 3d), a good linear correlation was observed. Such correlation suggests that the fracture toughness is also affected by the crystal size. Considering the form of dependence of compressive strength on the crystal size (cf. Supplementary Equation. 1 above), it is reasonable to postulate the following equation for the dependence of fracture toughness on porosity and crystal size:

$$
K_{I C}=K_{I O} G^{-m} e^{-n P}
$$

where $K_{I O}, m$, and $n$ are constants. To determine these constants using the experimental data provided by Supplementary Table 1, we use nonlinear least-square data-fitting using MATLAB which yielded $K_{I O}=30.1 M P a \cdot m^{0.5} \cdot \mu m^{0.3}, m=0.3$ and $n=1.43$. After substitution in Equation. (4):

$$
K_{I C}=(30.1) G^{-0.3} e^{-1.43 P}
$$

Equation. (5) graphically illustrating in (Figure 3f) in main text shows that the fracture toughness increased with decreasing both the porosity and the crystal size, and that the effect of decreasing the crystal size on fracture toughness was more pronounced than decreasing the porosity, which is similar to compressive strength as shown in (Figure 3e). Additionally, Equation. (5) provides a good prediction of the fracture toughness based on the experimental data with an R-value of 0.92 and a P-value of 0.002 (Figure 3d). 
Table S1: Gypsum cements prepared at 3 and 6 powder-to-liquid ratios

\begin{tabular}{|c|c|c|c|c|c|c|c|}
\hline $\begin{array}{c}\mathrm{P} / \mathrm{L} \\
\text { ratio }\end{array}$ & Group & $\begin{array}{c}\text { Porosity } \\
(\%)\end{array}$ & $\begin{array}{c}\text { Compressive } \\
\text { strength (MPa) }\end{array}$ & $\begin{array}{l}\text { Fracture } \\
\text { toughness } \\
\left(\text { MPa.m }^{1 / 2}\right)\end{array}$ & $\begin{array}{c}\text { Crystal } \\
\text { aspect ratio }\end{array}$ & $\begin{array}{c}\text { Crystal } \\
\text { diameter } \\
(\mu \mathrm{M})\end{array}$ & $\begin{array}{c}\text { Crystal } \\
\text { length } \\
(\mu \mathrm{M})\end{array}$ \\
\hline \multirow[t]{3}{*}{$6 \mathrm{~g} / \mathrm{ml}$} & Control & $2.6(0.5)$ & $46.7(0.7)$ & $0.42(0.01)$ & $9.13(3.1)$ & $1.16(0.5)$ & $10.7(3.4)$ \\
\hline & D-(-)-Tar & $7.8(1.7)$ & $53.0(2.4)$ & $0.53(0.06)$ & $2.9(1.4)$ & $2.4(1.2)$ & $6.86(3)$ \\
\hline & $\mathrm{L}-(+)-\mathrm{Tar}$ & $7.4(1.4)$ & $65.3(3.5)$ & $0.72(0.01)$ & $1.7(1.5)$ & $1.0(0.6)$ & $1.8(1.6)$ \\
\hline \multirow[t]{3}{*}{$3 \mathrm{~g} / \mathrm{ml}$} & Control & $25.4(1.0)$ & $21.2(1.8)$ & $0.28(0.01)$ & $7.3(3.1)$ & $1.34(0.7)$ & $9.86(2.2)$ \\
\hline & D-(-)-Tar & $36.4(1.8)$ & $29.0(0.9)$ & $0.36(0.02)$ & $2.6(1.2)$ & $2.5(0.9)$ & $6.65(1.7)$ \\
\hline & $\mathrm{L}-(+)-\operatorname{Tar}$ & $36.7(0.4)$ & $37.0(4.7)$ & $0.42(0.06)$ & $1.9(0.94)$ & $1.2(0.2)$ & $2.4(2.1)$ \\
\hline
\end{tabular}
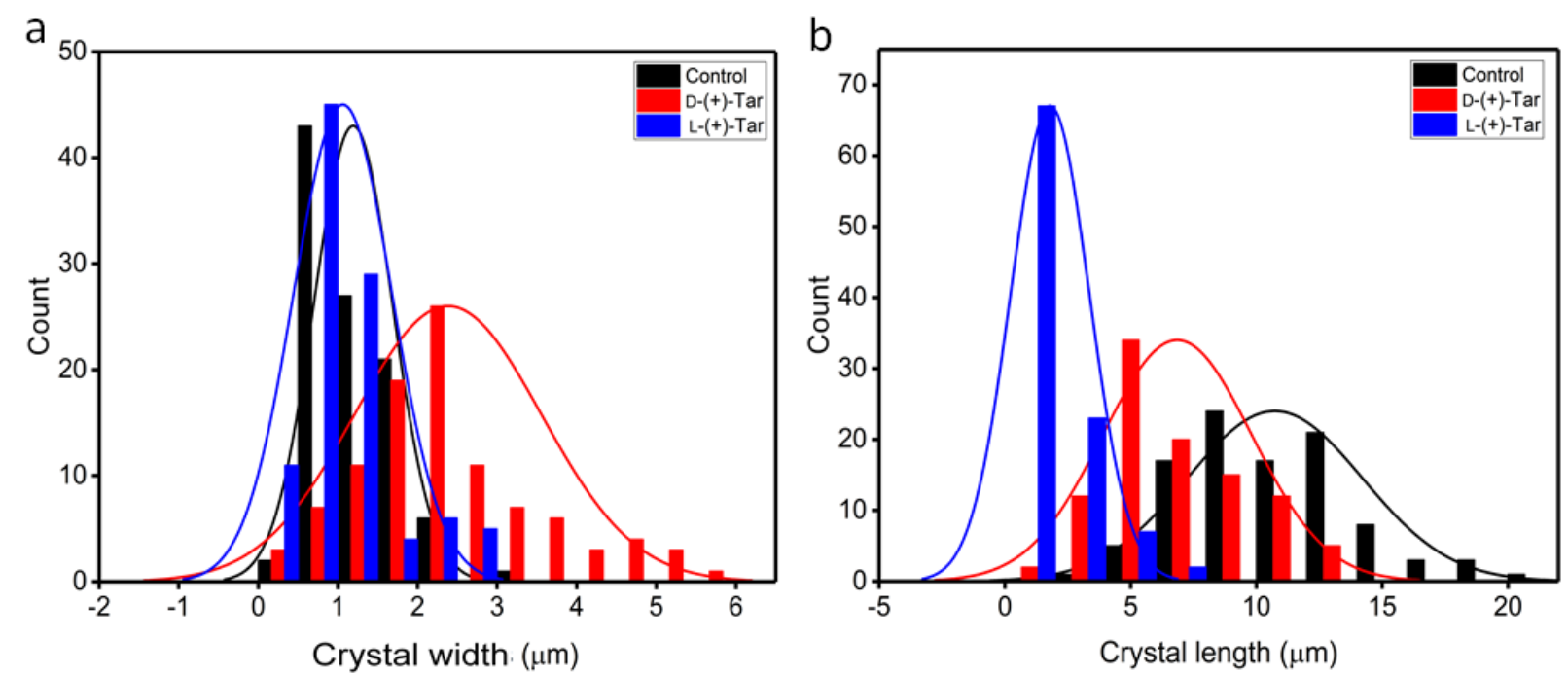

Figure S1. (a) Crystal size width and (b) crystal length of gypsum cements in absence of additives or in presence of D-(-)-tartaric acid (1M) or L-(+)-Tartaric acid

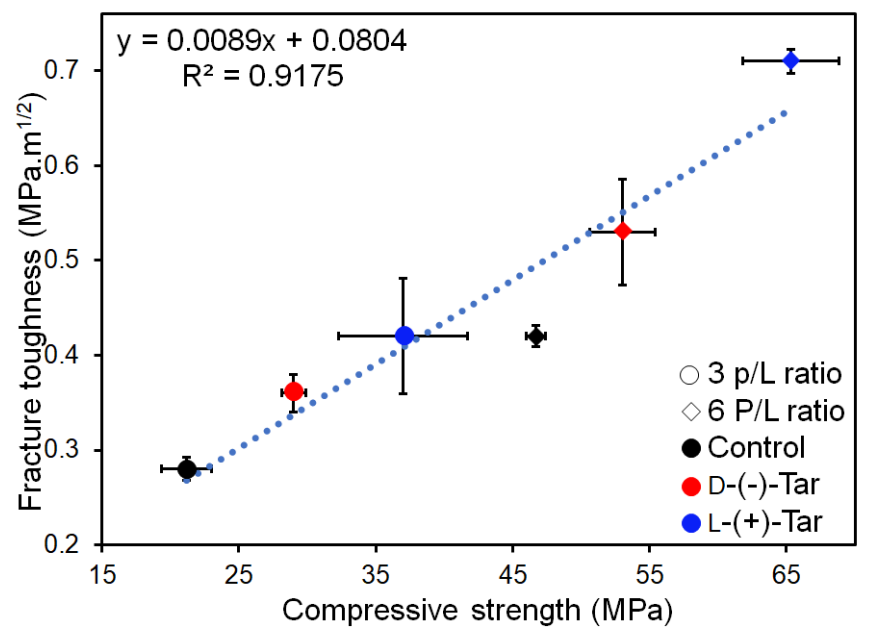

figure S2: Experimental fracture toughness (KIC) versus experimental compressive strength $(\sigma c o m p)$. The dotted line represents a linear fitting of the data. 

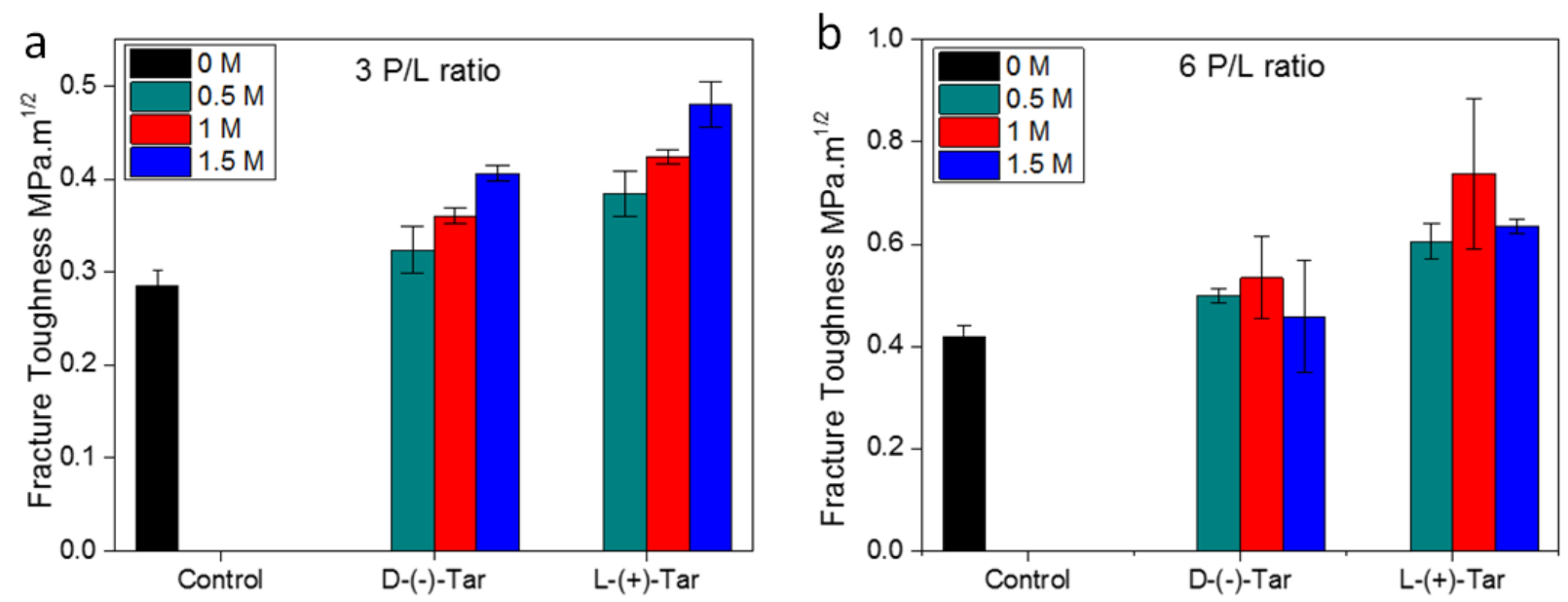

figure S3. Fracture toughness of gypsum cements prepared without additives or in the presence of different concentrations of D-(-)- and L-(+)-tartaric acid at (a) 3 powder/liquid ratio and (b) 6 powder/liquid ratio.
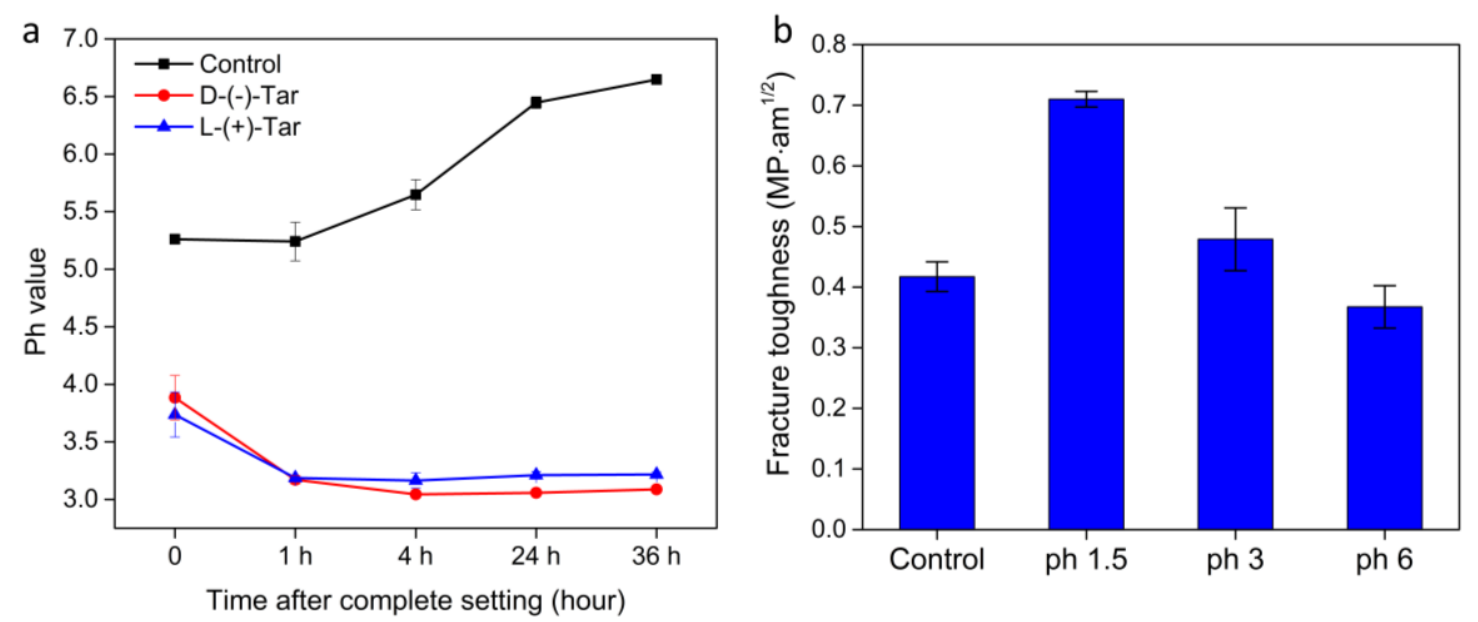

figure S4. (a) Ph of gypsum cements (after setting) prepared without additives or in presence of $1 \mathrm{M}$ D-()- and L-(+)-tartaric acid (b) Effect of tartrate ions Ph on the fracture toughness of gypsum cements prepared with $1 \mathrm{M} \mathrm{L}-(+)$-tartaric acid at 6 powder/liquid ratio

\section{Supplementary references}

1. KNUDSEN, F. P., Dependence of Mechanical Strength of Brittle Polycrystalline Specimens on Porosity and Grain Size. 1959, 42 (8), 376-387.

2. Rodríguez-Lorenzo, L. M.; Vallet-Regí, M.; Ferreira, J. M. F.; Ginebra, M. P.; Aparicio, C.; Planell, J. A., Hydroxyapatite ceramic bodies with tailored mechanical properties for different applications. 2002, 60 (1), 159-166.

3. Rice, R. W., Grain size and porosity dependence of ceramic fracture energy and toughness at 22 ${ }^{\circ} \mathrm{C}$. Journal of Materials Science 1996, 31 (8), 1969-1983. 